Rev. Adm. Saúde (On-line), São Paulo, v. 21, n. 82: e281, jan. - mar. 2021, Epub 24 mar. 2021 http://dx.doi.org/10.23973/ras.82.281

\title{
PERSPECTIVA
}

\section{A desigualdade do isolamento}

The Inequity of Isolation

\section{Simone Vais ${ }^{1}$}

1. Departamento de Medicina da Família e da Comunidade, Universidade da California, São Francisco, EUA

"Do berço ao túmulo" - essa é a promessa e o privilégio da medicina de família: a oportunidade de cuidar de indivíduos e famílias em todas as fases da vida. Para um estagiário de medicina de família, este privilégio tem um sabor ligeiramente diferente. É o privilégio de testemunhar os eventos que levam as pessoas ao hospital ao longo de sua vida - nascimento e morte e a doença entre eles. E como estagiária em meio a uma pandemia, aprendi que esse privilégio pode andar de mãos dadas com a dor. Hoje em dia, é a dor de testemunhar a profunda solidão criada pelo fechamento das portas do hospital a todos, exceto aos enfermos e às pessoas encarregadas de curá-los - uma solidão que parece inteiramente distinta em cada idade e fase da vida.

Nos últimos meses, quando aprendi a cuidar de bebês, selecionar antibióticos caros e dosar metadona, também aprendi que testemunhar o isolamento de meus pacientes e suas repercussões agora faz parte de meu trabalho. As restrições de visitação decretadas para conter a disseminação da covid-19 aumentaram muito o isolamento no hospital. Mais perturbador é que a ausência de entes queridos ao lado do leito significa que, à medida que nossos pacientes sofrem suas doenças, não há ninguém ao lado deles para fazer perguntas, advogar por testes adicionais, notar mudanças sutis no apetite ou comportamento, ou insistir que o problema que trouxe eles para o hospital sejam resolvidos antes de serem mandados para casa. Portanto, essas funções - observar, defender, acompanhar - também são meu trabalho agora. Devo preencher as lacunas deixadas pela ausência de entes queridos. $E$, como em todos os aspectos do meu trabalho, ainda estou aprendendo. 
Primeiro, estou aprendendo a ver. O cenário do hospital mudou, e estou aprendendo a ajustar minhas lentes para notar os efeitos dessa mudança.

Para a nova mãe na sala seis, pós-parto: vejo sua indignação quando digo que seu parceiro deve deixar o hospital agora. Com alguma apreensão, explico que, embora seu bebê permaneça internado para fototerapia, você está pronto para receber alta. Assim que tiver alta, você se tornará um visitante, o que torna seu parceiro o visitante número dois. No momento, nossa política é de um visitante por paciente, para limitar a propagação do vírus. Você percebe que essa regra significa perder o apoio da pessoa que esteve ao seu lado, segurando sua mão, durante vinte horas de trabalho de parto e ficar, exausta e delirando, sozinha com seu recém-nascido. Você está indignado. Obrigado por manifestar sua indignação e por me mostrar que preciso lutar por você e por uma solução diferente, que acaba sendo a transferência para a enfermaria de pediatria, onde permitimos duas visitas por vez. Você me ensina que essa também é a minha função agora: lutar por você hoje e repensar nossa política amanhã.

Para o jovem no corredor, considerando suas escolhas de como seu pai viverá seus últimos dias após uma longa batalha contra o câncer metastático: Vejo que você não tem escolha. Eu vejo seu desejo de trazê-lo de volta para casa com você. Ouvi dizer como você se sente preso porque não pode tirar uma folga do trabalho para cuidar dele e não tem recursos para contratar ajuda. Você entende que o asilo é sua única escolha, mas que eles em nossa região têm políticas de zero visitantes no momento. Você me pergunta: "Então, estou sendo forçado a mandá-lo embora para morrer sozinho?"

Vejo sua dor, a iniquidade dessa realidade. Nós fazemos um plano: vamos mantê-lo no hospital até que ele tenha a chance de se despedir de seus entes queridos. Pode demorar um pouco, pois mesmo para os "eminentes moribundos" permitimos apenas duas visitas por dia, mas seremos seu asilo pelo tempo que ele precisar. Obrigado por nos cutucar para empurrar de volta a pressão constante para descarregar para que possamos permitir que sua vida termine com a dignidade que ele merece, por me ajudar a ver que este é o meu trabalho também: encontrar soluções dentro dos sistemas que posso controlar, quando há tanto que não posso.

E para as filhas que estão juntas e preocupadas, esperando fora do serviço de emergência: vejo sua frustração quando você tenta descrever o comportamento e a memória de sua mãe em um dia normal. Eu ouço seu medo quando você conta que a encontrou deitada no chão do quarto, confusa e agora sendo forçada a imaginá-la deitada sozinha e confusa no pronto socorro. Você conta os obstáculos que enfrentou até agora: os médicos que aumentaram a confusão dela, com a barreira do idioma e aqueles que viram seu comportamento errático como um sintoma de demência, embora você saiba que não é. Você está certa em insistir que ela seria mais bem servida com você ao seu lado, pois sua confusão diminui enquanto trabalhamos para descobrir sua causa. Desta vez, eu não tenho uma solução alternativa. Ainda não sei como burlar as regras do pronto-socorro, às duas da manhã, para fazer você entrar, e sinto muito. Obrigado por sua empatia, mesmo no meio de sua frustração. Ligarei para você com frequência e verificarei como ela está, como 
se a amasse tanto quanto você. Esta noite, isso é o melhor que posso oferecer; mas amanhã vou compartilhar sua história para que possamos fazer melhor da próxima vez.

Estou tentando ver e responder: quebrar as regras, conceder mais um visitante, por mais uma hora. Para levá-lo para um passeio lá fora. Para pedir sua refeição favorita em seu restaurante favorito, como seu filho teria feito. Para garantir que suas preocupações, e as minhas em seu nome, sejam ouvidas por pessoas com poderes para abordá-las.

Sinto o peso do seu isolamento. Carrego o peso de saber que, embora eu possa entrar e sair do hospital livremente, você e seus entes queridos não podem. Vejo você de manhã cedo, antes da ronda médica e novamente enquanto me preparo para ir para casa passar a noite. Cada vez, percebo que você está sozinho e isso pesa sobre mim. No entanto, à medida que procuro aprender um sistema que é novo para mim, em um mundo que é novo para todos, às vezes esqueço que fazer algo a respeito desse isolamento também é meu trabalho agora. E quando eu esquecer, obrigado por me lembrar.

O isolamento durante a doença não é novo, mas seus efeitos e iniquidades são ampliados por essa pandemia. As restrições aos visitantes são medidas razoáveis de saúde pública, mas são inerentemente injustas. Pessoas com meios para cuidar de seus entes queridos em casa não sofrem as consequências dessas regras com tanta gravidade. Aqueles com smartphones e planos de dados podem se conectar apesar das regras. Tais desigualdades não significam que devemos eliminar totalmente os limites - infelizmente, não temos esse luxo. Mas em momentos de propagação de pandemia estável, mas não crescente, podemos reexaminar nossas regras e como aplicá-las.

Podemos trabalhar para garantir que os mais marginalizados entre nós não se tornem ainda mais vulneráveis porque não há ninguém ao seu lado para notálos, defendê-los e acompanhá-los.

Em nossos pacotes de serviços hospitalares e listas de verificação, revisamos sistematicamente detalhes importantes, mas facilmente esquecidos, todos os dias, antes de assinarmos cada nota. Ordem de dieta, profilaxia para trombose venosa profunda, código de status, contato de emergência. Acredito que é hora de adicionar isolamento a essas listas de verificação. Precisamos pensar pro ativamente sobre como o isolamento afetará as experiências e a saúde de nossos pacientes, para que não violemos inadvertidamente as regras apenas para pessoas que entendem o sistema e foram capacitadas para se defender dentro dele.

E precisamos de ajuda. Ajudar a ver, responder, defender e reformular o que significa cuidar bem de alguém durante a nossa crise atual - porque nosso trabalho é grande e novo e estamos aprendendo, e porque as lacunas deixadas por membros ausentes da família são grandes demais para preenchermos sem o suporte do sistema. Se o nosso sistema de saúde deve atender bem aos marginalizados entre nós, devemos lembrar que, enquanto os médicos são os únicos autorizados a ficar ao lado do leito, é nossa responsabilidade preencher o lugar de todos que não podem estar lá. Esse também é o nosso trabalho agora. 
Tradução livre de:

N Engl J Med 2021; 384:690-691

DOI: 10.1056/NEJMp2029725

Recebido: 09 de fevereiro de 2021. Aceito: 24 de março de 2021

(C) This is an Open Access article distributed under the terms of the Creative Commons Attribution License, which permits unrestricted use, distribution, and reproduction in any medium, provided the original work is properly cited 